\title{
Identidad personal e identidad corporal en el enfoque crítico
}

\section{kantiano}

Matías Oroño (UBA-CONICET)

matiasoro@gmail.com

Recibido 24/03/2017

Aprobado 23/04/2017

Resumen: En este trabajo analizamos el problema de la identidad personal en el marco de la filosofía crítica, teórica de Kant. Ofrecemos una interpretación del "Tercer paralogismo" y defendemos la tesis según la cual es posible reconstruir una noción kantiana de identidad personal que supone necesariamente la identidad corporal del ser humano. Concluimos que la identidad corporal es una condición necesaria (pero no suficiente) de la identidad personal. Según la interpretación aquí desarrollada, nos encontramos ante una noción de identidad personal que se despliega en el plano de una conciencia de sí como complejo psico-físico y reposa en última instancia sobre la identidad sustancial fenoménica del propio cuerpo.

Palabras clave: Kant; criticismo; tercer paralogismo; identidad personal; identidad corporal.

Abstract: In this paper we analyze the problem of personal identity within the framework of Kant's critical theoretical philosophy. We offer an interpretation of the "Third Paralogism" and defend the thesis, according to which, it is possible to reconstruct a Kantian notion of personal identity that necessarily supposes the corporeal identity of the human being. We conclude that the corporeal identity is a necessary condition -but not sufficient- of personal identity. According to the interpretation developed here, we are faced with a notion of personal identity that unfolds on the level of a self-consciousness as a psycho-physical complex and rests ultimately on the phenomenal substantial identity of the own body.

Key Words: Kant; criticism; third paralogism; personal identity; corporeal identity. 


\section{Introducción}

En este trabajo indagaremos la posibilidad de fundamentar la noción de identidad personal desde un punto de vista teórico-cognoscitivo en el marco del pensamiento crítico de Kant. Particularmente nos focalizaremos en el análisis del "Tercer Paralogismo de la identidad" (KrV, A 361-366) ${ }^{1}$ y dejaremos de lado los aspectos prácticos del tratamiento kantiano de la personalidad. ${ }^{2}$ Intentaremos defender la tesis según la cual desde un punto de vista cognoscitivo la única noción de identidad personal que subsiste es aquella que remite a un sujeto empírico que aparece de manera espacial a través de su propio cuerpo. Es decir, el sustrato fenoménico material provisto por el cuerpo propio es el único que permite predicar algún tipo de identidad análoga a la que presentan los objetos espaciales de nuestra experiencia ordinaria. Esta tesis implica que la pretensión de la psicología racional de derivar la identidad personal a partir de la mera representación "yo pienso", sin que intervengan elementos empíricos, fracasa por los siguientes motivos: 1. el "yo pienso" posee una identidad estrictamente formal $y$ no es posible identificar esta representación puramente intelectual con la identidad de un sustrato que se mantiene idéntico en diferentes tiempos; 2 . la única noción de identidad personal que podemos conocer es aquella que supone el aparecer empírico del cuerpo propio, con lo cual la identidad que se afirma no es la del alma, sino la del cuerpo humano. Esto nos conduce al interrogante acerca de si es posible pensar la identidad corporal en términos de identidad personal. Intentaremos señalar que en el mejor de los casos nos

1 Como es habitual, para referirnos a la Crítica de la razón pura utilizaremos las siglas KrV seguidas de la letra A (primera edición) y/o B (segunda edición) y el número de página. Véase: KANT, I., Crítica de la razón pura (traducción, notas e introducción de Mario Caimi). Buenos Aires, Colihue, 2007.

2 Bonaccini sostiene que un tratamiento completo de la identidad personal en Kant debería abordar los parágrafos 16, 24 y 25 de la Deducción Trascendental de las Categorías, la crítica a los Paralogismos, la Antropología y textos de filosofía práctica. Cfr. BONACCINI, J., "El problema de la identidad personal en el §16 de la Crítica de la razón pura”. En: Estudios de Filosofía. 39, 2009, pp. 39-54 (aquí: pp. 44-45). Por su parte, Ribeiro dos Santos realiza un análisis sobre la transformación semántica que sufre la noción de persona en Kant. Esta transformación se desplaza desde un plano metafísico-psicológico hacia uno moral, jurídico y político. Ribeiro dos Santos sostiene que, en última instancia, la persona no puede ser aprehendida de manera psicológica, sino que remite a un proceso que se da mediante la praxis humana. Cfr. RIBEIRO DOS SANTOS, L., “Do paralogismo logico da personalidade ao paradoxo moral da pessoa: génese e significado da antropologia moral kantiana”. En: Studia Kantiana. 11, 2011, pp. 7-40. 
hallaríamos ante una noción de identidad personal sumamente debilitada, pues lo único que podemos conocer es la identidad de la sustancia fenoménica subyacente al cuerpo humano, siendo la identidad personal del alma algo que solo puede ser pensado.

Consideramos que la crítica de Kant al razonamiento expuesto en el "Tercer Paralogismo" (KrV, A 361-366) puede ser analizada en dos partes. En primer término, vamos a ocuparnos de la línea argumental que subraya que la identidad personal no se deriva de la representación "yo pienso" (ver sección II de este trabajo). En segundo lugar, analizaremos la denominada "hipótesis del observador externo", cuyo análisis nos permite comprender que incluso desde el punto de vista de un observador externo es imposible afirmar el conocimiento de la identidad personal, a no ser que nos conformemos con una noción de identidad personal cuyo soporte ya no es el "yo pienso", ni el alma, sino el cuerpo del sujeto (ver sección III de este trabajo). Veremos que incluso la identidad del sustrato que subyace al aparecer del cuerpo propio es insuficiente para resolver el problema de la identidad personal. Ello es así puesto que el concepto de identidad personal que Kant discute en el contexto del "Tercer paralogismo de la identidad" se orienta hacia un sustrato autoconsciente, capaz de reconocer su propia identidad numérica en el trascurso del tiempo. Por su parte, la identidad corporal a la que arriba la crítica kantiana no pone de manifiesto un sustrato autoconsciente de su propia identidad sustancial, sino un sustrato fenoménico del cual se puede a lo sumo tomar conciencia, pero él mismo no es autoconsciente.

\section{El carácter no personal del yo de la apercepción trascendental}

Según Kant, un paralogismo lógico es aquél que es incorrecto debido a su forma, mientras que un paralogismo trascendental tiene su fundamento en una tendencia de la razón humana e implica una ilusión inevitable, aunque no insoluble. ${ }^{3}$ Los paralogismos que hallamos en el contexto de la "Dialéctica trascendental" de la KrV son justamente los de tipo trascendental, es decir, aquellos que son intrínsecos a la razón humana. Esto último pone de relieve que Kant no se encuentra discutiendo simplemente con un sistema filosófico - como podría ser el racionalismo moderno-

3 Cfr. KrV A 341/B 399. 
sino que está señalando una tendencia a cometer este tipo de falacias que es propia de la razón humana. No obstante, al leer los paralogismos pareciera que las doctrinas que se están discutiendo son aquellas que podrían ser atribuidas, en líneas generales, al racionalismo moderno. Creemos que esto puede interpretarse del siguiente modo: si bien los paralogismos trascendentales fueron cometidos de manera protagónica por filósofos que se alinean dentro del racionalismo moderno, ello no excluye que puedan ser formulados por otras corrientes de pensamiento, pues son falacias que se basan en una tendencia propia de la razón humana.

Así pues, en el marco del criticismo se estudia la legitimidad de "[...] una presunta ciencia, construida sobre la única proposición: Yo pienso [...]"4 . Esta pretendida ciencia es la doctrina racional del alma, la cual solo aspira a tener conocimientos que se derivan del concepto del yo. Si algún elemento empírico de nuestro pensar se mezclara entre los fundamentos de esta supuesta ciencia, nos hallaríamos ante una doctrina empírica del alma $-\mathrm{y}$ ya no ante una doctrina racional-. En este contexto, Kant afirma que:

Yo, como pensante, soy un objeto del sentido interno y me llamo alma. Aquello que es un objeto de los sentidos externos, se llama cuerpo. Según esto, la expresión: Yo, como ente pensante, significa ya el objeto de la psicología, la que se puede llamar doctrina racional del alma, si no pretendo saber del alma nada más que lo que, independientemente de toda experiencia (que me determina más precisamente e in concreto), puede ser inferido de este concepto $Y_{0}$, en la medida en que él se presenta en todo pensar. (KrV, A 342/B 400).

En este pasaje queda señalado de manera explícita que el cuerpo, como objeto de los sentidos externos, es uno de los elementos que no puede entremezclarse entre 4 KrV A 342/B 400. 
los fundamentos de la psicología racional. A partir de este "yo pienso", que acompaña a todo pensar, la psicología racional pretendería extraer conocimientos acerca del alma humana.

Aquí analizaremos el "Tercer paralogismo de la personalidad" tal como aparece en la primera edición de la $\mathrm{KrV} .{ }^{5}$ La estructura argumental del tercer paralogismo es la siguiente:

1) Lo que tiene conciencia de la identidad numérica de sí mismo en diferentes tiempos, es, en esa medida, una persona.

2) El alma es algo que tiene conciencia de la identidad numérica de sí misma en diferentes tiempos.

Conclusión: El alma es una persona.

Se ha señalado que la primera premisa parece retomar el concepto lockeano de persona tal como aparece desarrollado en el libro II de An Essay Concerning Human Understanding (1690), donde Locke entiende por "persona" un ser dotado de razón e inteligencia, que se considera a sí mismo como idéntico en diferentes tiempos y lugares. Ahora bien, para Locke la identidad personal no implica la identidad de una sustancia. Contra esta opinión Leibniz sostiene en los Nouveaux essais sur l'entendement par l'auteur du systeme de l'harmonie preestablie (1765) que la identidad de la conciencia supone la identidad sustancial del alma concebida como mónada. Si bien Kant no lo menciona, parece estar retomando esta discusión a lo largo del tercer paralogismo tal como es presentado y discutido en la primera edición de la $\mathrm{KrV}^{6}$

Tal como ha sido señalado por Ameriks, el punto débil de este paralogismo no radica en su forma lógica. Según este intérprete, aquello que Kant intentará atacar se encuentra en la segunda premisa del argumento: "el alma es algo que tiene conciencia

$5 \mathrm{KrV}, \mathrm{A} 361-366$.

6 Cfr. JÁUREGUI, C., Sentido interno y subjetividad. Un análisis del problema del auto-conocimiento en la filosofía trascendental de Kant. Buenos Aires, Prometeo, 2008, p. 136. 
de la identidad numérica de sí misma en diferentes tiempos". 7 La estrategia consistirá en sostener que el psicólogo racional confunde la identidad lógica del "yo pienso" de la apercepción trascendental que debe poder acompañar a cada una de mis representaciones con la identidad numérica de un objeto sustancial que podríamos identificar con el alma y a partir de esta identidad numérica inferir el carácter personal del alma. Por tanto, el objetivo central de la crítica kantiana a este paralogismo es demostrar que estamos incapacitados para afirmar a partir de la mera representación "yo pienso" la personalidad idéntica de sí mismo como alma. ${ }^{8}$

Comencemos reconstruyendo la crítica que Kant formula contra la pretensión de la psicología racional de atribuirle personalidad al "yo pienso". En primer lugar, se señala que poseemos un criterio para atribuirle identidad numérica a un objeto espacial, el cual consiste en observar los cambios que un objeto presenta en el trascurso del tiempo y determinar aquello que no cambia -i.e. que actúa como un sustrato material que posibilita los cambios-. Por el contrario, cuando intento conocerme a mí mismo, no encuentro nada que opere a la manera de un sustrato, sino que tan solo descubro un flujo de representaciones que se dan sucesivamente ante el sentido interno, en el cual nada permanece. Es decir, el yo empírico del sentido interno consiste en un flujo de representaciones en el cual nada es permanente.

En la medida en que soy consciente del flujo de representaciones, puedo tomar conciencia del "yo pienso" (i.e. nos introducimos en el terreno de la apercepción trascendental) que debe poder acompañar a cada una de estas representaciones. Noto así, que este "yo pienso" en tanto condición formal y universal de toda conciencia es idéntico a sí mismo durante todo el tiempo que soy consciente del flujo de mis representaciones. Para comprender esta identidad del "yo pienso" debemos recordar

7 Cfr. AMERIKS, K., Kant's Theory of Mind: An Analysis of the Paralogisms of Pure Reason. New York, Oxford University Press, 2000, p. 131.

8 Se ha señalado que lo que Kant está discutiendo es la pretensión de la psicología racional de afirmar mediante un mero análisis conceptual la permanencia absoluta (eterna) de un substrato acerca del cual no poseemos intuición sensible alguna. Es decir, lo que Kant discute es el valor cognitivo de la creencia en una identidad personal absoluta e incorruptible - pero no pone en duda el valor cognitivo de otras nociones más laxas de identidad personal, análoga a la identidad que podemos predicar, por ejemplo, de los objetos que nos rodean en la vida cotidiana-. Sobre esta cuestión cfr. BROOK, A., Kant and the Mind. Cambridge: Cambridge University Press, 1997, p. 183. 
los conceptos de unidad analítica y unidad sintética de la apercepción, tal como fueron presentados en el $\S 16$ de la KrV. La unidad analítica de la apercepción es aquella que afirma la identidad consigo mismo del yo que debe poder acompañar a cada una de sus representaciones (i.e. se afirma la identidad $\mathrm{Yo}_{\mathrm{o}}=\mathrm{Yo}$ ). Esta identidad solo se alcanza en la medida en que el yo unifica diversas representaciones en su propia conciencia. Es el mismo "yo pienso" el que enlaza el múltiple de la intuición que es aprehendido de manera sucesiva. Ahora bien, dado que el "yo pienso" es una representación puramente intelectual, no se da en el tiempo. De allí que la única vía para atribuirle al "yo pienso" identidad en diferentes tiempos es si se consideran las representaciones que son enlazadas y se reconoce que es el mismo "yo pienso" el que acompaña y enlaza las representaciones que ocupan diversos momentos en el flujo temporal. En este sentido, el reconocimiento de la identidad del yo de la apercepción trascendental en diferentes tiempos presupone la unidad sintética de un múltiple que se despliega temporalmente de manera sucesiva, de otro modo el yo trascendental no podría tener conciencia de su identidad consigo mismo en diferentes tiempos. Debe observarse que aquí no estamos afirmando que el "yo pienso" se despliegue temporalmente o tenga algún tipo de duración, sino que se trata de una forma que se mantiene idéntica a sí misma cuando consideramos su relación con diversas representaciones que se presentan intuitivamente de manera temporal. ${ }^{9}$ En suma, el "yo pienso" de la apercepción trascendental posee una identidad estrictamente formal que no implica la identidad numérica de algo efectivamente existente, ni mucho menos el carácter sustancial del yo. ${ }^{10}$

9 En una línea de interpretación análoga a la que estamos ofreciendo aquí, Brook sostiene que la identidad lógica del yo pienso remite a la condición meramente formal que posibilita que las representaciones sean algo para mí, pero tal identidad lógica no dice nada respecto de mi existencia real, locación, permanencia, etc. Asimismo, agrega que el "yo pienso" puede ser interpretado como la forma de nuestras representaciones. Así como las representaciones de los sentidos externos adoptan a priori la forma del espacio, las representaciones en general adoptan necesariamente la forma del yo, en el sentido de que todas y cada una de las representaciones aparecen como mías (en la medida en que el "yo pienso" debe poder acompañarlas). Cfr. Op. Cit. BROOK, A., Kant and the Mind. p. 199.

10 Una interpretación alternativa sobre el problema de la identidad personal en el $\S 16$ de la KrV es desarrollada por Bonaccini, quien afirma la identidad numérica del yo de la apercepción trascendental en diversos estados de conciencia. Cfr. Op. Cit. BONACCINI, J., "El problema de la identidad personal en el §16 de la Crítica de la razón pura", pp. 51-52. 
En la crítica al "Tercer paralogismo" Kant señala contra el psicólogo racional que esta identidad del "yo pienso" consigo mismo en diversos momentos no demuestra la identidad numérica del sujeto concebido como un sustrato real que permanezca a través de los cambios:

[...] la identidad de la conciencia de mí mismo en diferentes tiempos, es solo una condición formal de mis pensamientos y de la interconexión de ellos, pero no demuestra la identidad numérica de mi sujeto [...] ( $\mathrm{KrV}, \mathrm{A}$ 363)

Es decir, la psicología racional confunde la identidad meramente lógica o formal del yo trascendental con la identidad numérica de un sustrato real. El yo pienso es una condición meramente formal que no implica la identidad sustancial del sujeto. Esto es así en la medida en que la identidad lógica del "yo pienso" que puede expresarse mediante la formula "Yo=Yo" alude a una mera identidad formal que es condición de posibilidad de la unidad de la conciencia, señalando con ello que el mismo "yo pienso" debe poder acompañar a todas sus representaciones. ${ }^{11}$ Pero esta identidad formal del yo consigo mismo no implica necesariamente una identidad sustancial, pues para ello sería necesario realizar algún tipo de objetivación del yo, de modo que podamos identificarlo como un sustrato que permanece a través de los cambios que se dan en él. Ahora bien, es imposible efectuar este proceso de objetivación del yo como sustrato y sus accidentes. En primer lugar, la pretendida objetivación del "yo pienso" supone postular un nuevo "yo pienso" que haga posible la conciencia que toma por objeto al yo sustancial permanente con sus respectivos accidentes, generando con ello

11 Una análisis minucioso acerca del carácter yoico, no impersonal y estrictamente formal del principio de la apercepción trascendental se encuentra en: CAIMI, M., "Se piensa. Sobre una función del yo en la deducción transcendental". En: CAIMI, M. (compilador), Temas kantianos. Buenos Aires, Prometeo, 2014, pp. 95-111. Este autor sostiene contra la interpretación de Henrich (HENRICH, D., Identität und Objektivität. Heidelberg, Carl Winter, 1976, pp. 84 y ss.) que la apercepción reposa fundamentalmente sobre el aspecto de unidad, mientras que el aspecto de identidad desempeña una función subsidiaria que permite concebir adecuadamente la unidad. 
un regreso al infinito. En segundo término, el "yo pienso" constituye una representación meramente intelectual y por ello carece del material intuitivo necesario para la aplicación de las categorías. Kant afirma que debido a esta imposibilidad de objetivar al "yo pienso" debemos inferir que no lo conocemos y que podemos suponer tanto que permanece como un sustrato a través del tiempo, como que cambia con cada uno de nuestros pensamientos. Incluso podemos pensar en una trasformación sustancial constante de este sujeto-sustancia que hemos conjeturado y en una conservación de cada uno de los pensamientos pertenecientes a los sujetos anteriores. A fin de comprender esto con mayor detalle podríamos revisar un ejemplo introducido por Kant:

Una bola elástica que choca con otra en dirección rectilínea, le comunica a esta todo su movimiento, y por tanto, todo su estado (si solo se atiende a los lugares en el espacio). Ahora bien, según la analogía con cuerpos tales, suponed substancias, una de las cuales le infundiese a la otra representaciones juntamente con la conciencia de éstas; entonces se podría pensar toda una serie de ellas, la primera de las cuales comunicase su estado, junto con la conciencia de él, a la segunda; ésta comunicase su propio estado, juntamente con el de la sustancia anterior, a la tercera; y ésta, igualmente, comunicase los estados de todas las precedentes, junto con el suyo propio y la conciencia de [todos] ellos. Así, la última sustancia sería consciente de todos los estados de las que antes de ella fueron alteradas, como si fueran los de ella misma; porque ellos habrían sido transpuestos en ella, junto con la conciencia; y a pesar de ello, no habría sido ella la misma persona en todos estos estados. (KrV, A 363 - A 364, nota)

Por tanto, es posible concebir una trasformación de la propia persona sin renunciar a la identidad formal - meramente lógica - del yo trascendental, ni a los pensamientos de cada una de estas personas, los cuales serían transmitidos, junto con 
la conciencia de ellos -es decir, junto con el "yo pienso" - a las siguientes sustancias (personas). Algunos intérpretes han señalado que este experimento mental demuestra que es posible dar cuenta de la memoria, sin necesidad de postular un yo sustancial idéntico. Dado que la última bola elástica (sustancia) puede ser consciente de todos los estados pertenecientes a las bolas elásticas precedentes (sustancias anteriores), sería posible dar cuenta de la memoria sin necesidad de suponer un sustrato numéricamente idéntico. ${ }^{12}$

En suma, dado que no conocemos al "yo pienso" de la apercepción trascendental, podemos suponer tanto que él cambia, junto a las representaciones a las cuales acompaña, como que subsiste su identidad numérica. Con este razonamiento, Kant concluye que la identidad sustancial de la persona no se sigue de la mera identidad lógica del "yo pienso". Ahora bien, en el marco del criticismo kantiano, el concepto de identidad personal puede ser conservado bajo la condición de que no sea usado con intenciones de ampliar nuestros conocimientos, tal como lo pretendía la psicología racional. El concepto de identidad personal solo podría conservarse como una idea de la razón que permita sistematizar la experiencia al atribuir a un supuesto yo permanente las diversas representaciones empíricas. Pero este yo o alma, acerca del cual sería posible pensar la identidad personal -es decir, la permanencia sustancial- solo posee un rol regulativo que nos permite sistematizar la experiencia, sin constituir él mismo un objeto de conocimiento. ${ }^{13}$

\section{La hipótesis del observador externo y el sustrato material del cuerpo} propio

El texto kantiano presenta una segunda línea argumental, la cual se desprende de la hipótesis de un observador externo, el cual solamente puede identificarnos como

12 Cfr. Op. Cit. BROOK, A., Kant and the Mind. p. 200.

13 Baum analiza la distinción entre el yo lógico de la apercepción trascendental y el yo personal que es presupuesto en la discusión del "Tercer Paralogismo" y concluye que si bien este último no puede ser demostrado teóricamente a partir del yo lógico, ello no implica la imposibilidad de pensar la autonomía de la persona en un sentido práctico o moral. De este modo, sería posible la postulación de un sujeto personal y libre (que se eleva respecto de las determinaciones del mundo sensible), el cual es imputable por sus acciones. Cfr. BAUM, M., "Eu Lógico e Eu Pessoal em Kant”. En: Studia Kantiana. 4 (1), 2003, pp. 7-26. 
personas, si considera el aparecer fenoménico de nuestro cuerpo en el espacio. Es el cuerpo el que presenta un sustrato fenoménico permanente a través del tiempo. Si esto es correcto, los postulados del criticismo kantiano solo nos permiten predicar algún tipo de identidad personal, si tomamos en cuenta el aparecer fenoménico y por tanto empírico del propio cuerpo, quedando con ello desvanecidas las pretensiones de la psicología racional de afirmar la personalidad partiendo exclusivamente de la representación "yo pienso". ${ }^{14}$

Así pues, analicemos esta segunda línea argumentativa: Kant introduce la hipótesis de un observador externo que incluso admitiendo la existencia de un yo idéntico que acompaña a cada una de mis representaciones, no puede inferir de ello la permanencia del yo como un sustrato. ${ }^{15}$ Dado que la mirada del observador externo toma como punto de partida mi aparecer en el espacio, esto nos sugiere un camino para pensar la identidad personal a través de la consideración del propio cuerpo, pues éste último presenta una suerte de sustrato material permanente, análogo al de los

14 Existen diversos puntos de vista en torno a cómo debe ser comprendido ese sustrato permanente que logre dar cuenta de la personalidad en el marco del criticismo kantiano. Strawson sostiene que tal sustrato permanente solo puede ser hallado en referencia al cuerpo propio. Cfr. STRAWSON, P., The Bounds of Sense: An Essay on Kant's Critique of Pure Reason. London, Methuen, 1966, p. 168. Bennett sugiere que lo que Kant está mentando es un sustrato continuo absoluto y que no hay manera de hallarlo (lo cual no constituye un problema para Kant, puesto que se trataría de una mera reliquia de la psicología racional). Cfr. BENNETT, J., Kant's Dialectic. Cambridge, Cambridge University Press, 1974, pp. 103 y ss. Ameriks señala que si bien Strawson y Bennett interpretan de manera radicalmente opuesta el significado del sustrato que permitiría dar cuenta de la identidad personal, ambos concluyen afirmando (aunque Bennett de manera indirecta) que la identidad personal solo podría ser explicada por referencia a criterios fenoménicos ordinarios (e.g. nuestro cuerpo). Asimismo, Ameriks afirma que existe una tercera manera de interpretar la cuestión y consiste en aceptar la búsqueda de un sustrato permanente absoluto y hallarla por una vía racionalista, analizando el concepto del "yo". Cfr. Op. Cit. AMERIKS, K. Kant's Theory of Mind: An Analysis of the Paralogisms of Pure Reason. pp. 138 y ss. Según Ameriks, esta línea fue desarrollada entre otros por Henrich, Bird y Wollf, quienes hallan cierta base textual para identificar la identidad lógica del yo de la apercepción trascendental con la identidad real de un sustrato en el tiempo. Cfr. Op. Cit. HENRICH, D., Identität und Objektivität. p. 86; BIRD, G., Kant's Theory of Knowledge. London, Routledge and Kegan Paul, 1962, p. 121; WOLFF, R. P., Kant's Theory of Mental Activity. Massachusetts, Cambridge University Press, 1963, p. 107.

15 Kitcher sugiere que el observador podría atribuir estados cognitivos a la persona que está siendo observada y de ese modo inferir la existencia de un yo pensante permanente. No obstante, el observador sería incapaz de inferir una permanencia ininterrumpida del yo, debido a la simple razón de que existen fragmentos del tiempo, en los cuales el observador se ausenta o no puede atribuir estados de conciencia a la persona observada. Cfr. KITCHER, P., Kant's Transcendental Psychology. New York/Oxford, Oxford University Press, 1990. p. 197. 
restantes objetos espaciales, acerca de los cuales predicamos la permanencia en el espacio. A partir de la permanencia de un sustrato material en el aparecer fenoménico de mi cuerpo, el observador externo tendría un recurso para inferir la identidad personal del sujeto que es observado - aunque no considerado como alma, sino como un ser humano corpóreo-.

Cabe aclarar que no resulta evidente el motivo específico por el cual Kant recurre aquí a la hipótesis de un observador externo, sobre todo si se tiene en cuenta que para constituirnos como fenómenos espaciales hubiese bastado con considerar el propio punto de vista. Los intérpretes han ofrecido diversas interpretaciones sobre esta problemática. ${ }^{16}$ Sea como fuere que interpretemos la hipótesis del observador externo, pareciera que el único recurso que permite atribuirnos algún tipo de permanencia temporal - manteniendo con ello la noción de identidad personal- es la consideración de nosotros mismos como entidades psico-físicas (subrayando de ese modo la imposibilidad de aplicarle la categoría de sustancia no solo al yo trascendental, sino también al yo empírico del sentido interno). ${ }^{17}$

16 Brook sostiene que el observador externo constituye el punto de partida de la validez objetiva sobre las personas. Probablemente, lo que quiere mentar el autor es que el aparecer de mi yo como un objeto de los sentidos externos (i.e. como un ser humano) puede ser corroborado de manera intersubjetiva, a diferencia de lo que ocurre con las representaciones que sólo pertenecen a mi sentido interno. Cfr. Op. Cit. BROOK, A., Kant and the Mind. p. 201. Hughes subraya que el propio cuerpo no solo es un fenómeno espacio-temporal desde el punto de vista de un observador externo, sino también desde el propio punto de vista. Cfr. HUGHES, R., "Kant's Third Paralogism". En: Kant-Studien. 74 (4), 1983, pp. 405-411 (aquí: pp. 408-409). Según Bennett, el observador externo tendría la función de corregir una auto-atribución de identidad que posee defectos originados, por ejemplo, en fallas de la memoria. Cfr. Op. Cit., BENNETT, J., Kant's Dialectic. pp. 100 y ss. Por su parte, Keller sostiene que la función del observador externo no consiste tanto en corregir una falsa auto-atribución de identidad, sino en otorgarle objetividad a los propios estados de conciencia subjetivos. La perspectiva exterior permitiría relativizar la propia perspectiva meramente subjetiva, otorgándole de ese modo cierto valor objetivo. Cfr. KELLER, P., Kant and the Demands of Self-Consciousness. Cambridge, Cambridge University Press, 1998, pp. 175 y ss. Contra esta postura, Jáuregui subraya que no es la relativización de la propia perspectiva, sino la posibilidad de aplicarle a mi cuerpo la categoría de sustancia lo que le otorgaría al observador externo la posibilidad de constituirme como objeto. Cfr. Op. Cit., JÁUREGUI, C., Sentido interno y subjetividad. p. 140. Por su parte, Powell considera que la introducción del observador externo tiene por función subrayar que la permanencia a la cual aspira el psicólogo racional es diferente a la que suponemos como sustrato de los fenómenos espaciales, es decir, la permanencia de un yo pensante no puede ser identificada con la permanencia de un cuerpo en el espacio. Cfr. POWELL, T., Kant's Theory of SelfConsciousness. Oxford, Clarendon Press, 1990, p. 144.

17 Sobre esta cuestión cfr. Op. Cit. JÁUREGUI, C., Sentido interno y subjetividad. pp. 141 y ss. 
Ahora bien, la perspectiva introducida por el observador externo no resuelve de ningún modo el problema de la identidad personal tal como es planteado mediante los postulados de la psicología racional, pues la permanencia a la cual aspira el psicólogo racional es la del alma concebida como sustancia, mientras que la permanencia a la cual puede acceder el observador externo es la de un sustrato que aparece ante los sentidos externos. Puede objetarse que la permanencia de un sustrato corpóreo no implica en absoluto la permanencia de la persona tal como es concebida por la psicología racional. Mientras que en un caso se pretende inferir la permanencia del alma a partir de la identidad lógica del "yo pienso", en el otro se infiere la permanencia de un cuerpo a partir de observaciones referidas al sentido externo. ${ }^{18}$ Esta diferencia entre el punto de vista del observador y las pretensiones del psicólogo racional es advertida por Kant cuando afirma que el tiempo en el que me coloca el observador externo no es el mismo tiempo que se encuentra ligado a la identidad de mi conciencia (cfr. KrV, A 363).

Por último, quisiéramos señalar la existencia de un pasaje presente en la edición B de los "Paralogismos" que contrapone al alma como mero objeto del sentido interno con el enfoque que considera su vínculo con el propio cuerpo:

[...] sigue sin estar demostrada la permanencia del alma, como mero objeto del sentido interno; y sigue siendo aún indemostrable; aunque sea de por sí clara su permanencia en la vida, cuando el ente pensante (como ser humano) es a la vez, para sí mismo, un objeto de los sentidos externos; con lo cual, empero, no alcanza su propósito el psicólogo racional que intenta demostrar, por meros conceptos, la absoluta permanencia de ella incluso más allá de la vida. $(\mathrm{KrV}, \mathrm{B} 415)^{19}$

18 KLEMME, H., Kants Philosophie des Sulbjekts. Systematische und entwicklungsgeschichtliche Untersuchungen zum Verhältnis von Selbstbewußtsein und Selbsterkenntnis. Hamburg, Felix Meiner Verlag, 1996, pp. 334 y ss

19 El subrayado es propio. 
Mientras que la permanencia del alma como mero objeto del sentido interno sigue sin ser demostrada, no podemos negar su permanencia en la vida, si adoptamos un punto de vista diferente al del psicólogo racional y consideramos una conciencia de sí ya no únicamente como objeto del sentido interno, sino también como objeto del sentido externo. Así pues, el único recurso que parece subsistir en el marco del criticismo para predicar el conocimiento de la identidad personal consiste en partir de un modo de autoconciencia que se percata de su arraigamiento al cuerpo y renunciar al menos desde un punto de vista cognitivo a las tesis que le atribuyen subsistencia eterna al alma. Kant no lo explica, pero parece ser el sustrato fenoménico del propio cuerpo lo que permitiría aplicar la categoría de sustancia al cuerpo y pensar (aunque no conocer) el alma ligada a ese cuerpo. ${ }^{20}$

Está claro que el problema de la identidad personal permanece como un problema difícil de resolver en el marco teórico del criticismo kantiano. Ello es así, puesto que no encontramos una explicación satisfactoria acerca del modo en el cual la permanencia del cuerpo implica la permanencia de algo que podríamos llamar alma. ${ }^{21}$ Pareciera pues, que la referencia al observador externo en la edición A del tercer paralogismo, así como el texto perteneciente a la edición $B$, que recién hemos citado, solo pueden ofrecernos un criterio para afirmar la identidad corporal del ser humano, sin que ello implique una solución en torno al interrogante acerca de si podemos conocer la existencia de un sustrato autoconsciente (llámese "yo" o "alma") capaz de reconocer su propia identidad (temporal) en el transcurso de la vida. Dicho en otros

20 Vigo sostiene que en el marco del criticismo kantiano la identidad personal no se deriva a priori del "yo pienso" sino que se constituye siempre empíricamente (a posteriori). Asimismo, el autor sugiere en una línea de pensamiento husserliana que la concreción personal del yo remite a un sujeto actuante y portador de determinadas "disposiciones habituales". En ese sentido, la identidad personal no sería el punto de partida, sino el resultado de la actividad del sujeto actuante. Cfr. VIGO, A., "Persona, hábito y tiempo. Constitución de la identidad personal”. En: Anuario Filosófico. 26, 1993, pp. 271-287 (aquí: pp. 284 y ss.)

21 Tal como señala Ameriks, no debemos confundir un criterio de identidad personal con aquello que es constitutivo de la personalidad. El cuerpo propio es un criterio mediante el cual sería posible justificar nuestra creencia en un yo que posee identidad personal, pero ello no significa que el cuerpo mismo sea la persona idéntica. Ser trata pues de la distinción entre "ser una persona" y "ser públicamente determinable como una persona". Ameriks agrega que la permanencia fenoménica del propio cuerpo no implica la permanencia de alguna sustancia o inteligencia nouménica. Cfr. Op. Cit., AMERIKS, K., Kant's Theory of Mind: An Analysis of the Paralogisms of Pure Reason. pp. 144 y ss. 
términos, la identidad personal a la cual aspira el psicólogo racional remite a una dimensión que pertenece primordialmente a la autoconciencia -es decir, se aspira al conocimiento de sí mismo como algo que permanece idéntico a través del tiempo-. En lugar de ello, la identidad corporal del sustrato fenoménico que subyace al aparecer del cuerpo propio no remite a un modo de autoconciencia, ya sea que concibamos a esta última en su nivel trascendental o bien en el nivel empírico del yo que aparece mediante un flujo de representaciones sucesivas ante el sentido interno. Pareciera pues, que si pretendemos atribuirle algún valor cognitivo a la noción de identidad personal debemos cumplir al menos con dos requisitos: 1. debe tratarse de un conocimiento que se da mediante un modo de autoconciencia, 2. esta autoconciencia debe dirigirse hacia algún sustrato permanente, el cual como hemos visto puede ser hallado si nos consideramos como fenómenos del sentido externo. Por tanto, podría conjeturarse que es posible conocer la identidad personal bajo la condición de suponer un modo de autoconciencia que considere el aparecer del sí mismo no solo como un fenómeno del sentido interno, sino fundamentalmente como un fenómeno del sentido externo. Si esto es correcto, el yo psicológico debe ampliarse a un yo psico-físico. ${ }^{22}$

\section{Conclusiones}

Hemos analizado las críticas de Kant a las pretensiones de la psicología racional de conocer la identidad personal a partir la representación "yo pienso" y sin recurrir a ninguna consideración de carácter empírico. Hemos visto que la estructura del paralogismo que se discute adopta la siguiente estructura:

1) Lo que tiene conciencia de la identidad numérica de sí mismo en diferentes tiempos, es, en esa medida, una persona.

2) El alma es algo que tiene conciencia de la identidad numérica de sí misma en diferentes tiempos.

\footnotetext{
22 No pretendemos afirmar que la identidad personal pueda ser abordada plenamente por un modo de conciencia teórica, pues como ya hemos señalado al comienzo de este trabajo, la cuestión de la identidad personal en Kant implica la referencia a textos que exceden la dimensión teórico-cognoscitiva. Aquí solo hemos intentado señalar que si nos limitamos a su aspecto cognoscitivo, la identidad personal puede ser reconstruida en el marco del criticismo.
} 
Conclusión: El alma es una persona.

A la luz de lo que hemos argumentado en este trabajo, este paralogismo es falaz puesto que allí se confunde la identidad lógica del "yo pienso" de la apercepción trascendental con la identidad numérica de un sustrato autoconsciente. Creemos que en el marco del criticismo kantiano resta un margen para afirmar el conocimiento de la identidad personal, pero el costo implica modificar la segunda premisa y la conclusión del "Tercer paralogismo". La estructura del argumento que permitiría afirmar el conocimiento de la identidad personal es la siguiente:

1) Lo que tiene conciencia de la identidad numérica de sí mismo en diferentes tiempos, es, en esa medida, una persona.

2) El ser humano, en tanto unidad psico-física, tiene conciencia de la identidad numérica de sí mismo en diferentes tiempos (siendo el aspecto físico o corpóreo aquel sobre el cual reposa la conciencia de la identidad numérica de sí mismo en diferentes tiempos).

Conclusión: el ser humano es una persona.

Vemos pues que la crítica kantiana al "Tercer paralogismo de la identidad" nos otorga herramientas para reconstruir una noción de identidad personal cuyo fundamento no es el alma ni el "yo pienso", sino el ser humano auto-consciente concebido como entidad psico-física. Según la propuesta que aquí ofrecemos se trata de una identidad personal que se despliega en el plano de una conciencia de sí como complejo psico-físico y reposa en última instancia sobre la identidad sustancial fenoménica del propio cuerpo. Creemos que la identidad corporal, por sí misma, no puede identificarse con la identidad personal, ni implicar a esta última. Consideramos que el conocimiento de la identidad personal supone una conciencia de sí como ser humano (excediendo así la autoconciencia expresada por el "yo pienso" de la apercepción trascendental y aquella que se percata del flujo de representaciones del sentido interno) y supone por ello, la identidad corporal. Si esto es correcto, la identidad corporal del ser humano es una condición necesaria aunque no suficiente del conocimiento de la identidad personal. 


\section{Bibliografía}

- AMERIKS, K., Kant's Theory of Mind: An Analysis of the Paralogisms of Pure Reason. New York, Oxford University Press, 2000

- BAUM, M., “Eu Lógico e Eu Pessoal em Kant". En: Studia Kantiana. 4 (1), 2003

- BENNETT, J., Kant's Dialectic. Cambridge, Cambridge University Press, 1974

- BIRD, G., Kant's Theory of Knowledge. London, Routledge and Kegan Paul, 1962

- BONACCINI, J., "El problema de la identidad personal en el $\$ 16$ de la Crítica de la razón pura". En: Estudios de Filosofía. 39, 2009

- BROOK, A., Kant and the Mind. Cambridge: Cambridge University Press, 1997

- CAIMI, M., "Se piensa. Sobre una función del yo en la deducción transcendental". En: CAIMI, M. (compilador), Temas kantianos. Buenos Aires, Prometeo, 2014

- HENRICH, D., Identität und Objektivität. Heidelberg, Carl Winter, 1976,

- HUGHES, R., “Kant's Third Paralogism”. En: Kant-Studien. 74 (4), 1983

- JÁUREGUI, C., Sentido interno y subjetividad. Un análisis del problema del autoconocimiento en la filosofía trascendental de Kant. Buenos Aires, Prometeo, 2008,

- KANT, I., Crítica de la razón pura (traducción, notas e introducción de Mario Caimi). Buenos Aires, Colihue, 2007

- KELLER, P., Kant and the Demands of Self-Consciousness. Cambridge, Cambridge University Press, 1998,

- KITCHER, P., Kant's Transcendental Psychology. New York/Oxford, Oxford University Press, 1990.

- KLEMME, H., Kants Philosophie des Sulbjekts. Systematische und entwicklungsgeschichtliche Untersuchungen zum Verhältnis von Selbstbewußtsein und Selbsterkenntnis. Hamburg, Felix Meiner Verlag, 1996

- POWELL, T., Kant's Theory of Self-Consciousness. Oxford, Clarendon Press, 1990 
- RIBEIRO DOS SANTOS, L., "Do paralogismo logico da personalidade ao paradoxo moral da pessoa: génese e significado da antropologia moral kantiana". En: Studia Kantiana. 11, 2011

- StRAWSON, P., The Bounds of Sense: An Essay on Kant's Critique of Pure Reason. London, Methuen, 1966

- VIGO, A., "Persona, hábito y tiempo. Constitución de la identidad personal". En: Anuario Filosófico. 26, 1993

- WOLFF, R. P., Kant's Theory of Mental Activity. Massachusetts, Cambridge University Press, 1963 